\title{
Viruses, endoplasmic reticulum stress, and interferon responses
}

\author{
$\mathrm{BH} \mathrm{H}^{\star, 1}$ \\ 1 Department of Microbiology and Immunology, College of Medicine, The \\ University of Illinois at Chicago, 835 South Wolcott Avenue, Chicago, IL 60612 \\ USA \\ * Corresponding author: B He, Department of Microbiology and Immunology (M/ \\ C 790), College of Medicine, The University of Illinois at Chicago, 835 South \\ Wolcott Avenue, Chicago, IL 60612, USA. Tel: + 1312996 2391; \\ Fax: + 1312996 6415; E-mail: tshuo@uic.edu
}

Received 20.7.05; revised 02.11.05; accepted 04.11.05; published online 06.1.06 Edited by J Yuan

\begin{abstract}
Viral infection induces endoplasmic reticulum (ER) stress and interferon responses. While viral double-stranded RNA intermediates trigger interferon responses, viral polypeptides synthesized during infection stimulate ER stress. Among the interferon-regulated gene products, the double-stranded RNA-dependent protein kinase (PKR) plays a key role in limiting viral replication. Thus, to establish productive infection, viruses have evolved mechanisms to overcome the deleterious effects of PKR. It has become clear that ER stress causes translational attenuation and transcriptional upregulation of genes encoding proteins that facilitate folding or degradation of proteins. Notably, prolonged ER stress triggers apoptosis. Therefore, viruses are confronted with the consequences of ER stress. Emerging evidence suggests that viruses not only interfere with the interferon system involving PKR but also manipulate the programs emanating from the ER in a complex way, which may facilitate viral replication or pathogenesis. This review highlights recent progress in these areas.

Cell Death and Differentiation (2006) 13, 393-403.

doi:10.1038/sj.cdd.4401833; published online 6 January 2006
\end{abstract}

Keywords: virus; endoplasmic reticulum; interferon; unfolded protein; apoptosis

Abbreviations: ATF4, activating transcription factor 4; ATF6, activating transcription factor 6 ; $\mathrm{BiP}$, the ER chaperone immunoglobulin heavy-chain-binding protein; $\mathrm{CHOP}, \mathrm{C} / \mathrm{EBP}$ homologous protein; dsDNA, double-stranded DNA; ER, endoplasmic reticulum; GADD34, growth arrest and DNA damage-inducible protein 34; IRE1, ER transmembrane protein kinase/endoribonuclease; PACT, PKR-activating protein; PERK, PKR-like ER kinase; PKR, double-stranded RNA-dependent protein kinase; ssRNA, singlestranded RNA; UPR, the unfolded protein response; XBP1, Xbox-binding protein

\section{Introduction}

Virus infection of mammalian cells consists of a series of events, which involve entry, RNA expression and processing, polypeptide synthesis and modification, genome replication, and maturation. Remarkably, as intracellular parasites, viruses rely on the utilization of cellular machinery and resource to complete their life cycle. In this complex process, viruses synthesize double-stranded RNA intermediates and produce viral proteins within host cells. Consequently, viral replication elicits cellular responses, such as endoplasmic reticulum (ER) stress and interferon responses. It is, therefore, not surprising that viruses have evolved various mechanisms to cope with these responses that limit or inhibit viral replication.

The role of interferon in antiviral defense has long been recognized. This family of cytokines is produced in response to virus infection. ${ }^{1}$ Once bound to its receptor on the cell surface, interferon activates the Janus tyrosine kinase/signal transducer and activator pathway, which induces the expression of a wide spectrum of cellular genes. Among these that are extensively characterized is the doublestranded RNA-dependent protein kinase (PKR), a key player of antiviral action of interferon. ${ }^{2}$ In mammalian cells, the interferon-induced PKR is activated by double-stranded RNA. When activated, PKR phosphorylates the $\alpha$ subunit of translation initiation factor elF-2 (elF2 $\alpha)$. This leads to the shutoff of protein synthesis and thereby inhibition of viral replication. Moreover, PKR is involved in cell growth, differentiation, apoptosis, and possibly ER stress (Table 1). ${ }^{3-5}$

Recent evidence has suggested the importance of ER stress response in virus infection. ${ }^{5-8}$ As a processing plant for folding and post-translational modification of proteins, the ER is an essential organelle for viral replication and maturation. In the course of productive infection, a large amount of viral proteins are synthesized in infected cells, where unfolded or misfolded proteins activate the ER stress response. ER stress caused by viruses has been observed to modulate various signaling pathways leading to cell survival or cell death. ${ }^{9-11}$ Obviously, differential regulation of ER stress dictates the viral pathogenesis or replication. It has been suggested that in mammalian cells the ER chaperone immunoglobulin heavychain binding protein (BiP), also known as glucose-regulated protein 78 (GRP78), works as a master control interacting with three mediators: PKR-like ER kinase (PERK), activating transcription factor 6 (ATF6) and the ER transmembrane protein kinase/endoribonuclease (IRE1). ${ }^{12-14}$ In response to ER stress, these components function to reduce the levels of new proteins translocated into the ER lumen, to enhance the protein-folding capacity and secretion potential of the ER, and to facilitate transport and degradation of ER-localized proteins (Figures 1 and 2). 
Table 1 Viruses, ER stress and PKR-mediated IFN response

\begin{tabular}{|c|c|c|}
\hline Virus & Genome & Reported site(s) of interaction \\
\hline $\begin{array}{l}\text { Asfarviridae } \\
\text { African swine fever } \\
\text { virus }\end{array}$ & dsDNA & $\mathrm{BiP}$ and PERK \\
\hline $\begin{array}{l}\text { Herpesviridae } \\
\text { Cytomegalovirus } \\
\text { Herpes simples virus } 1\end{array}$ & $\begin{array}{l}\text { dsDNA } \\
\text { dsDNA }\end{array}$ & $\begin{array}{l}\text { XBP-1, ATF4, ATF6, and PKR } \\
\text { PERK and PKR }\end{array}$ \\
\hline $\begin{array}{l}\text { Hepadnaviridae } \\
\text { Hepatitis B virus }\end{array}$ & dsDNA & Bip \\
\hline $\begin{array}{l}\text { Papillomaviridae } \\
\text { Papillomavirus }\end{array}$ & dsDNA & GADD34 and PKR \\
\hline $\begin{array}{l}\text { Poxiviridae } \\
\text { Vaccinia virus }\end{array}$ & dsDNA & PERK and PKR \\
\hline $\begin{array}{l}\text { Bunyaviridae } \\
\text { Tula virus }\end{array}$ & ssRNA & BiP and caspase- 12 \\
\hline $\begin{array}{l}\text { Flaviviridae } \\
\text { Bovine viral diarrhea } \\
\text { virus } \\
\text { Hepatitis C virus } \\
\text { Japanese encephalitis } \\
\text { virus }\end{array}$ & $\begin{array}{l}\text { ssRNA } \\
\text { ssRNA } \\
\text { ssRNA }\end{array}$ & $\begin{array}{l}\text { BiP } \\
\text { BiP, PERK, XBP-1, and PKR } \\
\text { BiPand CHOP/GADD153 }\end{array}$ \\
\hline $\begin{array}{l}\text { Orthomyxoviridae } \\
\text { Influenza A virus }\end{array}$ & ssRNA & $\mathrm{BiP}, \mathrm{P} 58^{\mathrm{IPK}}$, and PKR \\
\hline $\begin{array}{l}\text { Paramyxoviridae } \\
\text { Respiratory syncytial } \\
\text { virus } \\
\text { Simian virus } 5\end{array}$ & $\begin{array}{l}\text { ssRNA } \\
\text { ssRNA }\end{array}$ & $\begin{array}{l}\text { BiP and caspase-12 } \\
\text { BiP and caspase-12 }\end{array}$ \\
\hline $\begin{array}{l}\text { Retroviridae } \\
\text { Mouse retrovirus }\end{array}$ & ssRNA & Bip \\
\hline $\begin{array}{l}\text { Rhabdoviridae } \\
\text { Vesicular stomatitis } \\
\text { virus }\end{array}$ & ssRNA & $\mathrm{BiP}, \mathrm{PERK}$ and PKR \\
\hline
\end{tabular}

$\mathrm{BiP}$ is a member of heat shock proteins that binds to properly folded and misfolded proteins. ${ }^{15}$ In normal cells, $\mathrm{BiP}$ associates with the luminal domains of PERK, ATF6, and IRE1. Under stress conditions, BiP is sequestered to misfolded or unfolded proteins in the ER, where PERK, ATF6, and IRE1 are released. BiP release from PERK or IRE1 leads to homodimerization of each protein through its luminal domain, which induces autophosphorylation and subsequent activation. ${ }^{13,16}$ Activation of PERK attenuates protein synthesis, whereas activation of IRE1 leads to the transcription induction of a subset of genes encoding protein degradation enzymes. ${ }^{17}$ In parallel, BiP release from ATF6 leads to the translocation of ATF6 from ER to the Golgi apparatus, where it is cleaved and activated. ${ }^{14}$ Activation of ATF6 stimulates the transcription of genes encoding chaperones that refold misfolded proteins. However, when cells are unable to recover from ER stress, apoptosis occurs.

ER stress and interferon responses reflect different adaptive cellular processes, which are triggered during virus infection. Notably, viral double-stranded RNA intermediates stimulate the interferon response, whereas unfolded or misfolded proteins impose ER stress. Thus, viruses are faced

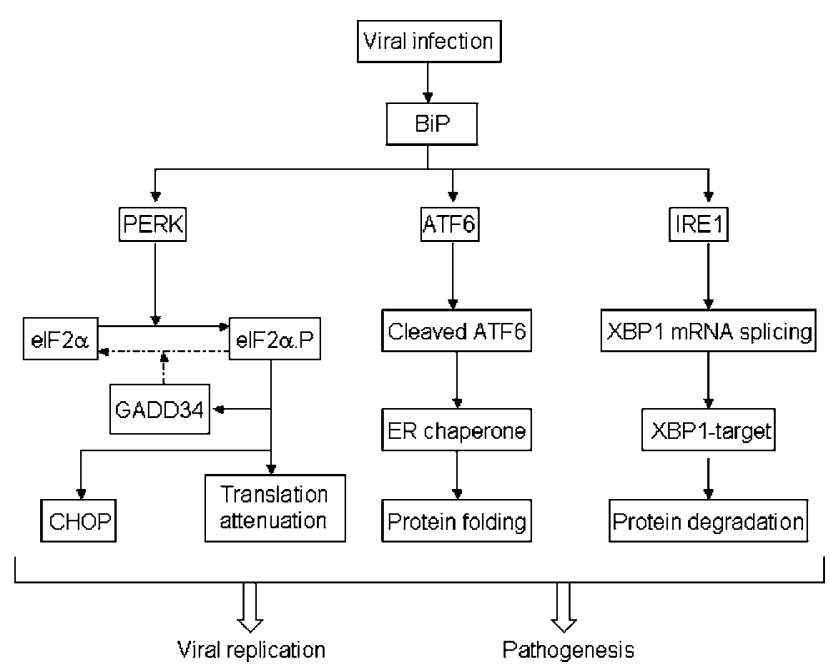

Figure 1 Modulation of UPR by viruses. Upon viral infection, unfolded proteins bind to the master control protein BiP, which thereby releases ER stress transducers, including PERK, ATF6, and IRE1. Thus, PERK undergoes dimerization, autophosphorylation, and subsequent activation. Activated PERK phosphorylates elF2 $\alpha$, which results in attenuation of general translation and induction of GADD34 and CHOP. Release of ATF6 from BiP leads to the translocation of ATF6 to the Golgi apparatus, where ATF6 is cleaved to yield a truncated form that is capable of stimulating the expression of chaperone genes in the nucleus. Release of IRE1 from BiP permits its dimerization and activation. Activated IRE1 facilitates the splicing of XBP1 mRNA, which encodes a transcription factor leading to the expression of the UPR target genes. Viruses encode functions that inhibit one or more steps in these signaling pathways. The balance between viral stimulation and inhibition determines the pathogenesis or replication of viral infection. Arrows represent activation of components or processes in the ER stress pathway upon viral infection

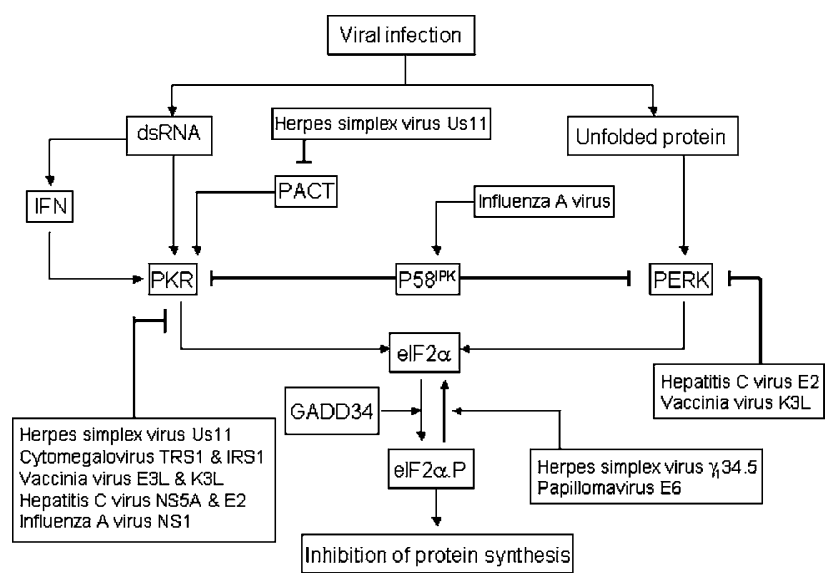

Figure 2 The $\alpha$ subunit of elF2 connects ER stress and interferon responses. Viral infection produces signals that activate PKR and PERK pathways, respectively. Double-stranded RNA produced by virus triggers the production of interferon, which upregulates PKR expression. Furthermore, double-stranded RNA binds to and activates PKR, which phosphorylates elF2 $\alpha$ and inhibits shutoff of protein synthesis. Unfolded protein activates PERK, which also phosphorylates elF2 $\alpha$. There are three cellular proteins that regulate PKR and PERK in response to different signals. PACT, a stress-activated protein, binds to and activates PKR. P58 ${ }^{\mathrm{KK} P}$, an ER stress-inducible protein, is capable of binding to PKR as well as PERK. Binding of P58 $8^{\mathrm{K} P}$ to the two kinases suppresses their activities. GADD34, an ER stress-inducible protein, mediates dephosphorylation of elF2 $\alpha$ by recruiting protein phosphatase 1 . Examples of viruses that inhibit the interferon response mediated by PKR and ER stress response are listed. Thick lines denotes inhibition or negative regulation, whereas arrows represent positive regulation or activation 
with the consequences of these cellular responses. Numerous studies demonstrate that virus infection activates PKR which plays a pivotal role in the antiviral action of interferon. ${ }^{2}$ As expected, PKR becomes a target of many viruses. Some examples are hepatitis $C$ virus, influenza virus, vaccinia virus, papillomavirus, herpes simplex virus, and cytomegalovirus. However, the impact of ER stress on viral infection has only been recognized recently. Several studies suggested a connection of the ER stress response with viral replication. These include members of the flavivirus family, bovine viral diarrhea virus, Japanese encephalitis virus, and hepatitis $\mathrm{C}$ virus. $^{9-11}$ Furthermore, other viruses have been shown to regulate ER stress, such as respiratory syncytial virus, simian virus 5, Tula virus, African swine fever virus, herpes simplex virus, and cytomegalovirus. ${ }^{7,8,18-21}$ This review will summarize recent progress on ER stress relevant to viral replication. Furthermore, it will highlight the regulation of the interferon system involving PKR in the context of ER stress upon virus infection.

\section{Interaction with GRP78/BiP: Virus Triggers}

As a resident of $\mathrm{ER}$ chaperone, the expression of $\mathrm{BiP}$ is upregulated in response to ER stress in mammalian cells. ${ }^{22}$ Although the effect of $\mathrm{BiP}$ induction on virus replication is not fully understood, accumulating evidence suggests that one or more viral proteins trigger BiP expression during virus infection. This phenotype becomes apparent in cells infected with paramyxoviruses, such as simian virus 5 and respiratory syncytial virus. ${ }^{18,23}$ In addition, infection of cells with other RNA viruses, for example, flaviviruses and hantavirus, stimulates $\mathrm{BiP}$ expression. ${ }^{10,11,19}$ Intriguingly, simian virus 5 induces the synthesis of several cellular proteins, including a $78-\mathrm{kDa}$ protein, $\mathrm{BiP}^{23}$ Besides the hemagglutinin-neuroamindase glycoprotein $(\mathrm{HN})$, simian virus 5 encodes the fusion glycoprotein, a small nonglycosylated integral membrane protein, the viral membrane protein, the major nucleocapsid protein, and the nucleocapsidassociated protein $L, P$, and $V$, respectively. However, among these viral proteins, only synthesis of the $\mathrm{HN}$ glycoprotein stimulates BiP expression. ${ }^{24}$ In virus-infected cells, the $\mathrm{HN}$ glycoprotein is synthesized on membrane-bound ribosomes, inserted into the ER, and then transported via the exocytic pathway to the cell surface. It seems that production of a specific viral protein in the ER stimulates transcriptional activation of BiP.

Previous studies with hemagglutinin of influenza virus revealed that the presence of misfolded viral proteins in the ER signals the induction of $\mathrm{BiP}$ and GRP94. ${ }^{25}$ Influenza hemagglutinin is synthesized as a monomer that is translocated across the ER membrane and assembled into a trimer. During maturation, hemagglutinin mutants which are blocked of transport from the ER are defective in protein folding. Thus, unlike wild-type hemagglutinin, the misfolded hemagglutinin induces the synthesis of Bip and GRP $94 .{ }^{26}$ Recent work by Liberman et al. ${ }^{27}$ showed that ecotopic expression of the E2 protein, but not E1, core, and NS3 proteins, from hepatitis $\mathrm{C}$ virus activates the promoter of GRP78/BiP. Consistent with this result, mammalian cell line stably expressing the E2 protein has an elevated level of BiP. Hepatitis $\mathrm{C}$ virus encodes a single polypeptide precursor, which is cleaved into the mature structural (core, E1, and E2) and nonstructural (NS2NS5B) proteins. As glycoprotein E2 is an ER resident with its carboxyl-terminal domains anchored in the ER membrane, it is postulated that E2 protein activates transcription of BiP indirectly by influencing an intracellular signaling pathway rather than acting in the nucleus. ${ }^{27}$ Upon expression, the $\mathrm{E} 1$ and E2 proteins form a heterodimer. In the folding process of the $E 1$ and $E 2$ proteins, a large portion of these proteins are trapped in aggregates, which may trigger BiP expression. ${ }^{28}$ Interestingly, hepatitis $\mathrm{C}$ virus replicons expressing only nonstructural proteins are also capable of stimulating BiP expression. ${ }^{29}$ Hence, either the process of viral replication or nonstructural proteins of hepatitis $C$ virus are capable of inducing BiP expression.

Early experiments suggested that BiP associates transiently with folding intermediates of viral glycoproteins. ${ }^{25,30,31}$ By binding to viral proteins, BiP performs at least two distinct functions in virus-infected cells. It is a chaperone that facilitates folding or assembly of viral proteins along the maturation process. Furthermore, it is also a sensor to detect unfolded or misfolded viral proteins. In simian virus 5-infected cells, HN specifically associates with BiP during glycoprotein folding. ${ }^{24,30}$ Elimination of glycosylation sites in HN renders the protein incapable of folding into a native conformation. Immunoprecipitation assays suggest that BiP associates with WT HN transiently, whereas it becomes more stably associated with misfolded $\mathrm{HN}^{24}$ Although the glycosylation mutant of $\mathrm{HN}$ expresses at a lower level, it induces a comparable level of BiP induction as compared to WT HN. A similar phenotype is noted with glycoprotein $\mathrm{G}$ of vesicular stomatitis virus, hemagglutinin of influenza virus, and glycoprotein E2 of hepatitis C virus. ${ }^{25,28,31}$ Collectively, these experimental data support a model in which interaction of BiP with misfolded or unfolded viral proteins triggers the ER stress response during viral infection. Clearly, additional studies are required to understand the molecular mechanisms that underlie these observations.

\section{The PERK Pathway: Virus Modulation}

Several lines of evidence have indicated a link of viral replication to the PERK pathway. $5,7,8,10,20,21$ In the early phase of ER stress, accumulation of unfolded or misfoled protein activates PERK, which then phosphorylates elF-2 $\alpha$ at serine 51 . This leads to inhibition of general protein synthesis and reduces the protein load in the ER. ${ }^{32}$ However, elF- $2 \alpha$ phosphorylation also induces the expression of activating transcription factor 4 (ATF4), a transcription factor that stimulates the expression of C/EBP homologous protein (CHOP), as well as growth arrest and DNA damage-inducible protein 34 (GADD34). ${ }^{32} \mathrm{CHOP}$, also known as growth arrest and DNA damage-inducible protein 153 (GADD153), is a dominant-negative inhibitor of the CCAAT/enhancer-binding proteins. When expressed in mammalian cells, $\mathrm{CHOP} /$ GADD153 facilitates apoptosis. ${ }^{33}$ GADD34 is expressed under conditions of DNA damage, growth arrest, and 
differentiation. ${ }^{34}$ The biochemical function of GADD34 was initially identified by genetic analysis. ${ }^{35}$ When expressed in the context of herpes simplex virus genome, GADD34 rescued protein synthesis in virus-infected cells. Further clue as to the cellular target of GADD34 has come from the yeasttwo-hybrid screen, which identified GADD34 as a regulatory subunit of protein phosphatase 1. Interestingly, the carboxylterminus of GADD34 recruits protein phosphatase 1, forming a high-molecular-weight complex that dephosphorylates elF-2 $\alpha^{36,37}$ In uninfected cells, GADD34 is a component of the PERK pathway that serves to relief translation repression during ER stress. ${ }^{38}$ Thus, GADD34 controls ER stressinduced translation inhibition as well as gene expression under stress conditions in the ER.

The carboxyl-terminus of GADD34 is highly homologous to the corresponding region of the $\gamma_{1} 34.5$ protein encoded by herpes simplex viruses. Thus, the domain shared by the two proteins may perform a common function. An interesting observation came from the analysis of ER stress in cells infected with herpes simplex virus $1 .{ }^{20}$ Herpes simplex virus-1 is a DNA virus whose gene expression is regulated in a cascade fashion. In cells infected with herpes simplex virus 1 , PERK is activated, as seen by an increase in autophosphorylation of PERK over the course of virus infection. Notably, phosphorylation of PERK is dependent on the production of viral protein synthesis. As PERK possesses an ER-luminal regulatory domain and a cytoplasmic kinase domain, processing or accumulation of viral proteins in the ER presumably facilitates the oligomerization of PERK. Although herpes simplex virus 1 infection activates PERK, elF2 $\alpha$ remains in the unphosphorylated state and viral polypeptide synthesis is normal in infected cells. This suggests that herpes simplex virus 1 stimulates and then disarms the activity of PERK. Indeed, the $\gamma_{1} 34.5$ protein, a virulence factor encoded by herpes simplex viruses, plays a critical role in mediating elF2 $\alpha$ dephosphorylation. ${ }^{20,36}$ The expression of the $\gamma_{1} 34.5$ protein alleviates the translation arrest in mammalian cells treated with dithiothreitol and thapsigargin, two compounds that induce unfolded protein response..$^{20}$ Like its cellular homolog GADD34, the carboxyl-terminal domain, the $\gamma_{1} 34.5$ protein is required to recruit protein phosphatase 1 to dephosphorylate elF-2 $\alpha$ and block translation shutoff during virus infection. ${ }^{36}$ Thus, the conserved carboxyl-terminal domain of the $\gamma_{1} 34.5$ protein represents a functional module. A hypothesis derived from these analyses is that, in order to cope with ER stress, herpes simplex virus acquired the $\gamma_{1} 34.5$ protein in order to antagonize the activity of PERK during its evolution. While this suggests a potential viral mechanism to modulate ER stress, it remains unknown whether the $\gamma_{1} 34.5$ protein regulates the transcription of host genes required for ER stress response that may affect viral virulence in vivo.

Recent studies have shown that cytomegalovirus and African swine fever virus also perturb the PERK pathway. ${ }^{8,21,39}$ Cytomegalovirus is a $\beta$-herpesvirus, whose gene expression occurs in an ordered temporal pattern. Compared to the prototype herpes simplex virus- 1 , it is a slowly replicating virus. In cells infected with cytomegalovirus, PERK is not phosphorylated in the early phase. As viral replication proceeds, there is an increase in the level of PERK phosphorylation later in infection, indicating that PERK is activated. However, there is only a limited extent of phosphorylation of elF-2 $\alpha$, which coincides with increased expression of ATF4. Despite phosphorylation of PERK and elF- $2 \alpha$, translation is not attenuated by cytomegalovirus infection. This observation implies that a viral mediated function may act downstream of elF-2 $\alpha$ phosphorylation. Currently, it is not clear which gene product(s) is involved in reducing phosphorylation of elF-2 $\alpha$ during the ER stress. African swine fever virus is a DNA virus, which uses the ER as a site for assembly and envelopment. Thus, replication of African swine fever virus is expected to induce ER stress. However, in virus-infected cells, African swine fever virus does not induce PERK activation. Furthermore, African swine fever virus is capable of blocking the expression of $\mathrm{CHOP} /$ GADD153-mediated dithiothreitol, thapsigargin, and other agents. ${ }^{8}$ It will be interesting to identify gene products that inhibit PERK activation.

In addition, RNA viruses that employ the ER as a site for viral replication and maturation have been shown to regulate PERK. For example, a cytopathic strain of bovine viral diarrhea virus, a member of flaviviruses, activates PERK and increases elF-2 $\alpha$ phosphorylation. ${ }^{10}$ During peak times of virion production, PERK phosphorylation is maximal. This suggests the level of ER stress signaling increases as viral gene products accumulate during infection. Accordingly, infected cells undergo apoptosis with increased expression of GADD153/CHOP and caspase-12. This phenotype is not associated with the noncytopathic strain of bovine viral diarrhea virus, which tends to cause chronic infection. Another example is the E2 protein encoded by hepatitis $C$ virus. ${ }^{40}$ When expressed, the E2 protein binds to PERK as a pseudosubstrate and may sequester it from its normal substrate elF2 $\alpha$. Although a direct link between hepatitis $\mathrm{C}$ virus and PERK is not known in infected cells, ecotopic expression of the E2 protein inhibits PERK phosphorylation and enhances translation, which is believed to contribute to persistent hepatitis $C$ virus infection. Additional work is needed to test this hypothesis. Thus, differential modulation of the PERK pathway is probably related to the biological properties of viruses.

\section{Regulation of the ATF6 and IRE1 Pathways by Viruses}

Compared to PERK, ATF6 and IRE1 are two components that function in the late stages of the unfolded protein response (UPR).$^{41}$ ATF6 resides in the ER membrane with a cytosolic amino-terminal domain and an ER luminal carboxyl-terminal domain. As a result of its activation, the amino-terminal domain of ATF6 is released by proteolysis. This portion of ATF6 translocates to the nucleus, where it cooperates with other proteins to form a complex that induces the expression of genes coding for chaperones or folding enzymes. ATF6 also upregulates the expression of $X$-box-binding protein (XBP1) mRNA, a substrate of IRE $1{ }^{42}$ IRE1 is a protein with an ER luminal amino-terminal domain, a transmembrane domain, a serine/threonine kinase domain, and carboxylterminal endonuclease domain in the cytoplasm. Under 
ER stress, IRE1 oligomerizes, autophosphorylates, and removes an intron from the XBP1 mRNA, which produces a transcription factor that activates target genes, for example, ER degradation-enhancing $\alpha$-mannoside-like protein (EDEM), which facilitates the degradation of misfolded proteins.

Replication of hepatitis $C$ virus has been shown to stimulate the ATF6 pathway, but suppress the IRE1-XBP1 pathway. ${ }^{29,43}$ In cells containing hepatitis $C$ virus replicons, subgenomic replication promotes the cleavage of ATF6, producing a $50-\mathrm{kDa}$ fragment that corresponds to the amino-terminal domain of ATF6. In correlation, there is an increased transcriptional level of $\mathrm{BiP}$, an ER luminal chaperone. As the ribonucleoprotein complex of hepatitis $\mathrm{C}$ virus is associated with the ER membrane, viral replication may stimulate expression of BiP/GRP78. As hepatitis $C$ virus replicons only express the structural proteins, it is not clear which nonstructural protein is involved in the induction of ATF6. Recent experiments suggest that subgenomic replication of hepatitis $\mathrm{C}$ virus reduces properly folded major histocompatibility complex class I, which is attributed to a decline in protein glycosylation. ${ }^{44}$ It is possible that unfolded MHC class I may account for the activation of ATF6. With respect to regulation of XPB1 by ATF6, it is notable that hepatitis $C$ virus replicons stimulate accumulation of more unspliced XBP1 mRNA as compared to cells without hepatitis $C$ virus replicons. Spliced XBP1 mRNA is also detected in cells containing hepatitis $C$ virus replicons. Surprisingly, transactivating activity of XBP1 is inhibited in cells with hepatitis $C$ virus replicons as measured by reporter assays. In parallel, ER-associated protein degradation is reduced in cells carrying hepatitis $\mathrm{C}$ virus replicons. A model to reconcile these findings is that hepatitis $C$ virus encodes a function to block the effect of IRE1-XBP pathway, which enhances the translation of viral proteins.

In view of ER stress mediated by ATF6 and IRE1, a different pattern is observed in cells infected with cytomegalovirus. ${ }^{21}$ Infection of cytomegalovirus causes a transient increase in $\mathrm{BiP}$ levels at the early phase of viral replication, but BiP returns to basal levels at the later stage. This coincides with the appearance of other markers of UPR. In the early phase of infection, the increased BiP may inhibit the ER stress response by interacting with PERK, ATF6, and IRE1. Thus, cytomegalovirus appears to control the level of $\mathrm{BiP}$ that regulates the onset of ER stress. In this regard, the Us11 gene product physically interacts with $\mathrm{BiP}^{39}$ The expression of cytomegalovirus Us11 in mammalian cells is sufficient to trigger UPR, as manifested by upregulation of Bip and production of spliced XBP-1 mRNA. This response is dependent on its interaction with a cellular protein Derlin-1 although the underlying mechanism is not known. Surprisingly, cytomegalovirus infection does not result in the proteolytic cleavage of ATF6. The full-length ATF6 is present throughout viral replication. Nevertheless, there is a limited expression of XBP1 mRNA in virus-infected cells. It seems that cytomegalovirus stimulates splicing of XBP1 in the later stages of infection as measured by RT-PCR analysis. Yet, transcriptional activation of the $X B P 1$ target gene is inhibited in virus-infected cells.

\section{Viruses and Apoptosis in ER Stress}

When unfolded proteins continue to accumulate beyond the capacity of the ER, apoptosis may occur. Under the ER stress, $\mathrm{CHOP}$ is activated to facilitate cell death. The downstream targets of CHOP remain unknown, but CHOP-mediated apoptosis has been coupled to a pathway that suppresses $\mathrm{Bcl}-2$ expression, depletion of intracellular glutathionine, and an increase of free radicals. ${ }^{33,45}$ Another pathway involves the activity of IRE1, TRAF2, and caspase-12. When activated, IRE1 recruits TRAF2 and c-Jun $\mathrm{N}$-terminal inhibitory kinase; thus, IRE1 transmits a signal via apoptosis signaling kinase c-Jun N-terminal kinase. This cascade triggers caspase-12 activation and subsequent apoptosis. ${ }^{46-48}$ Several viruses induce apoptosis mediated by ER stress. ${ }^{10,11,19}$ Infection of Japanese encephalitis virus exhibits severe cytopathic effect, which is associated with apoptosis, as measured by nuclear condensation and DNA laddering. As Japanese encephalitis virus infection alters the structure of the $E R$, it is not surprising that the expression of CHOP is enhanced. Notably, the level of CHOP induced seems to correlate with the extent of apoptosis in infected cells. Overexpression of $\mathrm{Bcl}-2$ reduces the virus induced cell death. In addition to CHOP, Japanese encephalitis virus infection also activates p38 MAPK. Inhibition of p38 MAPK activity alleviates apoptosis induced by Japanese encephalitis virus. Similarly, a cytopathic strain of bovine diarrhea virus induces apoptosis by stimulating $\mathrm{CHOP}$ activation, whereas the virus infection causes phosphorylation of PERK and elF-2 $\alpha$. In cells undergoing apoptosis, the levels of $\mathrm{Bcl}-2$ and glutathione are reduced. Collectively, these observations suggest that virus infection activates the p38 MAPK, which then acts on CHOP to initiate the death signal in infected cells.

Recent analysis suggests that Tula virus infection activates the JNK pathway. ${ }^{19}$ Notably, Tula virus infection leads to apparent phosphorylation of JNK1, and JNK2 to a lesser extent. As viral infection proceeds, both phosphorylated and nonphosphorylated c-Jun is dramatically increased. Furthermore, addition of JNK inhibitor II reduced the cleavage of PARP in infected cells. Thus, activation of the JNK pathway may contribute to the cell death mediated by Tula virus. In addition, cleavage of BAP31, a proapoptotic protein, correlates well with the activation of caspase-8. Virus infection also activates capsase-12. This activation is a late event in response to accumulation of misfolded protein in the $E R$, which can be blocked by the inhibitor z-VAD-fmk. Apoptosis induced by a cytopathic strain of bovine diarrhea virus coincides with caspase-12 activation. Further, infection with respiratory syncytial virus also activates caspase-12, and inhibition of caspase-12 by antisense oligonucleotides markedly suppresses apoptosis induced by respiratory syncytial virus. In fact, in cells infected with Tula virus, caspase-12, caspase-8, and caspase- 3 are all activated. The kinetics of caspase-12 activation is earlier than that of caspase- 8 and caspase-3, suggesting that caspase-12 might be an initiator caspase required for transduction of the death signal from the $E R$ in infected cells. It is unknown how viruses affect the upstream modulators leading to caspase-12 activation.

Although virus-mediated apoptosis in ER stress has been recognized, the biological significance of such a process is not 
well defined. Simian virus 5 infection enhances the expression of BiP and GRP94. However, this does not trigger apoptosis. ${ }^{7}$ A mutant simian virus 5 with a truncation of the $V$ protein induces cell death mediated by ER stress. Accordingly, the expression of CHOP is drastically increased and caspase-12 is activated. In a mouse model, simian virus 5 replicates more efficiently as compared to the $\mathrm{V}$ deletion mutant. This experimental model suggests that it is beneficial for simian virus 5 to prevent host cells from undergoing apoptosis mediated by ER stress. It should be stressed that the situation is more complex in other virus systems. For instance, it is generally less clear why some viruses promote ER-mediated apoptosis. It has been reported that murine retroviruses cause a spongiform neurodegenerative disease, which is determined by properties of viral envelope proteins. ${ }^{6}$ Infection of cells with the virulent strain $\mathrm{FrCas}^{\mathrm{E}}$ stimulates the expression of $\mathrm{BiP}$ and $\mathrm{CHOP}$, whereas infection with an avirulent strain F43 has no effect. Importantly, the envelope protein from F43 binds to BiP transiently and is processed normally through the secretory pathway. However, the envelope protein from $\mathrm{FrCas}^{\mathrm{E}}$ binds to $\mathrm{BiP}$ for a prolonged period and is degraded by the proteosome. Thus, the virulent strain may cause ER stress that mediates microglial cell death and consequently results in neuronal degeneration. These studies suggest that ER-mediated apoptosis induced by virus may be related to the pathogenesis of viral infection.

\section{ER Stress and Interferon Responses: The elF2 $\alpha$ Connection}

Unfolded proteins stimulate ER stress pathways, whereas dsRNA produced by viruses triggers the interferon pathway. These stress-responsive pathways converge at the $\alpha$ subunit of translation initiation factor 2 , which is essential for protein synthesis. To date, four different elF $2 \alpha$ kinases have been identified. ${ }^{49,50}$ These are the heme-regulated inhibitor (HRI), the homolog of Saccharomyces cerevisae protein kinase GCN2, PKR, and PERK (also known as pancreatic elF2 $\alpha$ kinase PEK). These kinases regulate the phosphorylation state of elF- $2 \alpha$ in response to heme deficiency, amino-acid starvation, dsRNA, and misfolded protein, respectively. Among these kinases, PKR as well as PERK are activated by virus infection. Notably, PKR is a cytosolic as well as nuclear protein, which acts as an intracellular receptor for dsRNA produced by viral replication. In contrast, PERK is an ER-resident membrane protein that transmits ER stress signal. Thus, PKR and PERK may coordinate to control viral replication.

PKR is a $68 \mathrm{kDa}$ protein that is subjected to two levels of regulation. ${ }^{2}$ First, it is induced by interferon. In normal cells, PKR is present at a low level and remains inactive. In the presence of interferon, the expression of PKR is elevated. Secondly, PKR is activated by dsRNA. Biochemical characterization suggested that PKR contains two copies of dsRNA-binding domains in the amino-terminus and a serine/ threonine kinase domain in the carboxyl-terminus. PKR binds dsRNA with high affinity and is activated by low concentrations of dsRNA. Upon binding of dsRNA, PKR forms a homodimer and autophosphorylates on multiple serine/ threonine residues. These series of events convert PKR into an active enzyme, which is capable of catalyzing the phosphorylation of a number of substrates, including elF-2 $\alpha$ at serine 51 . Phosphorylation of elF-2 $\alpha$ increases its affinity for guanine nucleotide exchange factor elF-2B, thus sequestering elF-2B in an inactive complex with phosphorylated elF-2 and GDP. Consequently, elF-2B is not available to catalyze nucleotide exchange on nonphosphorylated elF-2, leading to the shutoff of protein synthesis.

PKR is a multifunctional protein that also regulates apoptosis, cell proliferation, signal transduction, and differentiation. ${ }^{3}$ Overexpression of PKR has been suggested to inhibit cell proliferation in yeast, insect, and mammalian cells. ${ }^{51-53}$ Several studies showed that the expression of PKR mediates apoptosis. ${ }^{54,55}$ In contrast, the expression of catalytically inactive mutants of PKR in NIH3T3 cells results in tumorigenicity in nude mice, which is attributed to a dominant-negative effect of mutant PKR. ${ }^{53}$ Mouse embryo fibroblasts derived from $\mathrm{PKR}-1-$ mice are resistant to cell death induced by dsRNA and lipopolysaccharide. ${ }^{56} \mathrm{PKR}$ has been suggested to be involved in dsRNA signal transduction pathways leading to NF- $\kappa$ B activation and the p38 mitogenacitvated kinase pathway. ${ }^{57,58}$ In PKR-/-, but not wild-type cells, dsRNA fails to induce NF- $\kappa$ B activation, which correlates with the lack of interferon- $\beta$ production.

In addition to dsRNA, PKR activity is positively regulated by a cellular protein called PKR-activating protein (PACT)/ RAX ${ }^{59,60}$ This protein was identified as a PKR interacting protein by the yeast two-hybrid screen. PACT/RAX hetrodimerizes with PKR and activates it in the absence of dsRNA in vitro. PACT/RAX is expressed in most cell types. In mammalian cells treated with arsenite, thapsigargin, hydrogen peroxide, and interleukin-3 deprivation, PACT/RAX is rapidly phosphorylated and associates with $P K R$, which is followed by activation of PKR and elF- $2 \alpha$ phosphorylation. In this respect, it is notable that PKR is activated in mammalian cells in response to treatment with tunicamycin or thagasgagine, which causes ER stress by inhibiting protein folding. ${ }^{4,5}$ Therefore, PACT/RAX may be a stress-mediated activator of PKR.

Studies have pointed to $\mathrm{P} 58^{\mathrm{IPK}}$ as a tetratricopeptide repeat domain protein that negatively regulates both PKR and PERK. ${ }^{61-64}$ P58 ${ }^{\mathrm{IPK}}$ was originally characterized as an influenza virus-activated protein that interacts with the kinase domain of PKR and inhibits its activity. In normal cells, P58 IPK associates with a heat shock protein 40 and forms an inhibitory complex. Cellular stress or virus infection induces dissociation of $\mathrm{P} 58^{\mathrm{IPK}}$ from heat shock protein 40 . Therefore, the released $\mathrm{P} 58^{\mathrm{IPK}}$ can bind to PKR and disrupt its activity. In response to serum starvation or heat shock, P58 ${ }^{\mathrm{IPK}}$ also interacts with $\mathrm{P} 52^{\mathrm{rlPK}}$, a protein homologous to heat shock protein $90 .^{65}$ The response of $\mathrm{P} 58^{\mathrm{IPK}}$ activation to both influenza virus infection and cellular stress suggests that it is a multifunction protein. Recent work by Katze et al. ${ }^{62}$ showed that $\mathrm{P} 58^{\mathrm{IPK}}$ interacts with $\mathrm{PERK}$ and inhibits its activity. Overexpression of $\mathrm{P} 58^{\mathrm{IPK}}$ reduces elF- $2 \alpha$ phosphorylation mediated by PERK in mouse embryonic stem cells. On the other hand, deletion of P58 $8^{\mathrm{IPK}}$ increases elF-2 $\alpha$ phosphorylation and induction of $\mathrm{CHOP}$ and $\mathrm{BiP}$. Moreover, P58 ${ }^{\mathrm{IPK}}$ expression is induced by tunicamycin as well. This is 
consistent with the observation that the P58 ${ }^{\mathrm{IPK}}$ promoter bears an element that is commonly found in the promoter region of other genes induced by UPR. Thus, $\mathrm{P} 58^{\mathrm{IPK}}$ is also a component of the system that regulates unfolded protein response.

As mentioned earlier, GADD34 regulates the phosphorylation state elF-2 $\alpha$, which is a physiological substrate for PKR and PERK. Expression of GADD34 is dependent on phosphorylation of elF- $2 \alpha$, which stimulates translation of transcription factor ATF4. ${ }^{32}$ When induced, GADD34 recruits cellular protein phosphatase 1 to mediate elF- $2 \alpha$ phosphorylation. Thus, it is a control point of a negative-feedback loop that terminates the signals from PERK. In general, PKR and PERK are activated in response to different stimuli. However, a crosstalk exists between the PKR and PERK pathways. ${ }^{5}$ In response to vesicular stomatitis virus infection, phosphorylation of PKR is diminished in PERK-/- mouse fibroblasts (MEF) as compared to wild-type MEFs. In correlation, vesicular stomatitis virus replicates very efficiently in PERK-/- MEFs. This result suggests that PERK plays a role in controlling virus infection. Importantly, tunicamycin induces phosphorylation of PKR in PERK $+/+$, but less so in PERK-/- MEFs. Therefore, the antiviral action of PERK is mediated by PKR. The mechanism by which vesicular stomatitis virus activates PERK has not been elucidated. One interesting issue is how PERK regulates PKR. It should be pointed out that PKR may be considered as a member of the ER stress response system. In support of this notion is the recent finding that PKR is involved in ER-stress-mediated apoptosis. In neuroblastoma cells treated with tunicamycin, levels of phosphorylated PKR is increased in the nucleus. ${ }^{4}$ Together, these observations imply that coordinated interaction of PERK and PKR plays a critical role in regulating ER stress or interferon responses during viral replication.

\section{Virus Inhibition of the Interferon Response Mediated by PKR}

It is well established that PKR plays a critical role in the antiviral action of interferon. As viruses synthesize doublestranded RNA during their replication, the interferon system will be activated upon virus infection. This is apparently detrimental to virus replication in the host cells. To survive, viruses have evolved a variety of mechanisms to disarm the interferon system. ${ }^{1,2}$ This includes inhibition of PKR activation, the prevention of elF- $2 \alpha$ phosphorylation, or the degradation of PKR. For example, adenovirus VAI RNA, vaccinia virus K3L protein, hepatitis C NS5A protein, and influenza virus-induced p58 protein interact with PKR and block its activation. The herpes simplex virus $\gamma_{1} 34.5$ protein directs the cellular protein phosphatase 1 to dephosphorylate elF-2 $\alpha$, whereas poliovirus employs a cellular proteinase to degrade PKR. In addition, viruses employ countermeasures to inhibit interferon production or signal transduction initiated by interferons.

It is apparent that while suppressing the interferon response mediated by PKR, viruses also inhibit the ER stress regulated by PERK. Such viral strategies have been suggested to operate in some DNA as well as RNA viruses. These include herpes simplex virus, cytomegalovirus, hepatitis $\mathrm{C}$ virus, vaccinia virus, influenza virus, and perhaps papillommavirus. Herpes simplex viruses are inherently resistant to interferon in infected cells. Among herpes simplex virus genes that interfere with interferon responses, the $\gamma_{1} 34.5$ protein is well characterized. In cell culture, herpes simplex virus infection leads to activation of PKR, but only infection of the $\gamma_{1} 34.5$ null mutant causes phosphorylation of elF- $2 \alpha$, and subsequently attenuation of protein translation. ${ }^{66} \mathrm{~A}$ unique feature of herpes simplex virus is that during virus infection, the $\gamma_{1} 34.5$ is expressed to recruit cellular protein phosphatase 1, forming a high-molecular-weight complex that dephosphorylates elF- $2 \alpha{ }^{36,67}$ Accordingly, the $\gamma_{1} 34.5$ protein-mediated elF- $2 \alpha$ dephosphorylation contributes to viral resistance to the antiviral effect of interferon- $\alpha / \beta .^{68}$ This function maps to the carboxyl-terminal domain that is homologous to the corresponding domain of GADD34, which functionally substitutes for the $\gamma_{1} 34.5$ protein in the context of herpes simplex virus genome. ${ }^{35}$ Whether GADD34 has a role in interferon response in uninfected cells has not been established. Nevertheless, herpes simplex virus infection stimulates transient expression of GADD34. Given the role of GADD34 in ER stress, it is interesting that herpes simplex virus infection activates PERK and mediates elF- $2 \alpha$ dephosphorylation by the $\gamma_{1} 34.5$ protein. $^{20}$ These results support the hypothesis that, during the evolution, the $\gamma_{1} 34.5$ protein is adapted from host cells to cope with ER stress and interferon responses. In this context, it is noteworthy that, in mammalian cells, the E6 protein of papillomavirus associates with the GADD34-PP1 complex and facilitates elF-2 $\alpha$ dephosphorylation induced by the activation of PKR. ${ }^{69}$ Thus, a strategy similar to that used by herpes simplex virus may be employed by papillomavirus. Additional studies will be required to determine whether this mechanism does indeed operate under the conditions of viral infection.

Herpes simplex virus 1 also encodes the Us11 protein that binds to and inhibits PKR. ${ }^{70}$ The carboxyl-terminus of the Us11 protein contains an RNA-binding motif that prevents PKR activation. This portion of the Us11 protein also inhibits the activation of PKR by PACT/RAX in vitro. ${ }^{71}$ It is not known whether herpes simplex virus infection regulates PACT/RAX, which is capable of activating PKR. In virus-infected cells, Us11 is expressed at the late phase of virus life cycle. When its expression is shifted from a late to early kinetics, it prevents the shutoff of protein synthesis in virus-infected cells, suggesting that herpes simplex virus may have an additional way to block the antiviral action of PKR. ${ }^{72}$ It has been suggested that the Us11 protein functions to inhibit PKR in the late stage of infection and thereby complements the activity of the $\gamma_{1} 34.5$ protein. ${ }^{70}$ Further work is required to understand the precise role of Us11 in herpes simplex virus infection.

Another virus that regulates the activity of PKR and probably ER stress is vaccinia virus. Vaccinia virus encodes two gene products, $E 3 L$ and $K 3 L$, both of which confer viral resistance to interferon. ${ }^{73-75}$ The E3L protein, synthesized early during viral infection, contains an amino-terminal ZDNA-binding domain and a carboxyl-terminal domain with a typical dsRNA-binding motif. ${ }^{74}$ The carboxyl-terminus of E3L sequesters dsRNA and prevents the activation of PKR and phosphorylation of elF- $2 \alpha$. In addition, E3L prevents the 
activation of $2^{\prime}-5^{\prime}$ oligoadenylate synthetase. E3L deletion mutant is highly sensitive to interferon. In cell culture, the carboxyl-terminus, but not amino-terminus of E3L, is required for viral infection. However, the full-length of E3L is essential for viral pathogenesis in mice. ${ }^{76}$ The $\mathrm{K} 3 \mathrm{~L}$ protein has homology to elF2 $\alpha$ and acts as a pseudosubstrate for PKR in competition with elF $2 \alpha$, consequently, suppressing phosphorylation of elF $2 \alpha$ and the shutoff of protein synthesis. ${ }^{77}$ Studies suggest that E3L and K3L may determine viral host range in infected cells. ${ }^{75}$ The $E 3 L$ gene is required for viral replication in HeLa cells, but not in BHK cells. On the other hand, $K 3 L$ gene is required for viral replication in BHK cells, but is dispensable for viral replication in HeLa cells. The biological basis for this is not fully understood. Interestingly, in a heterologous system, K3L also binds to PERK and inhibits its activation. This raises the possibility that $\mathrm{K} 3 \mathrm{~L}$ interferes with the ER stress response. ${ }^{78}$ Consistent with this notion, vaccinia virus infection does not lead to phosphorylation of PERK. ${ }^{79}$ Recent studies with cytomegalovirus revealed that TRS1 and closely related IRS1 can each rescue a vaccinia mutant that has deletion of the E3L gene. TRS1 is an RNAbinding protein that may function like E3L of vaccinia virus. Thus, cytomegalovirus has two genes that function in blocking the PKR-mediated antiviral pathway. ${ }^{80}$

The NS5A protein of hepatitis $C$ virus is a phosphoprotein that interacts with PKR and inhibits its activation. ${ }^{81}$ The involvement of NS5A in hepatitis $C$ virus resistance to interferon is initially suggested by clinical studies with hepatitis $\mathrm{C}$ virus $1 \mathrm{~b}$ subtype from a Japanese isolate. ${ }^{82}$ Notably, a cluster of amino-acid mutations within a discrete region in NS5A seems to correlate with increased resistance of HCV$1 \mathrm{~b}$ to interferon. This region, termed the interferon-sensitivity determining region (ISDR), is thought to mediate viral resistance to interferon therapy. ${ }^{83}$ In supporting this observation, NS5A was found to bind to and inactive $\mathrm{PKR}$ in vitro. Furthermore, mutations in the ISDR region disrupted the interaction between NS5A and PKR. ${ }^{81,84,85}$ Paradoxically, the involvement of ISDR is less clear based on clinical studies from Europe and North America. ${ }^{86,87}$ It is clear that the clinical response to interferon therapy is a complex process that likely involves multiple viral as well as host factors. Nonetheless, expression of NS5A in a number of cell lines reduces the antiviral effect of interferon on replication of vesicular stomatitis virus or encephalomyocarditis virus. ${ }^{85}$ The mechanism by which NS5A works remains controversial. This may partly result from the fact that NS5A regulates a number of cellular pathways. ${ }^{88}$ Recent studies suggest that replication of hepatitis $C$ virus replicons corresponds with the ability of NS5A to block the activation of PKR and interferon regulatory factor $1{ }^{89}$ Mutations in the PKR-binding domain of NS5A lead to the induction of regulatory factor 1 -dependent antiviral genes and concomitant reduction in efficiency of viral RNA replication, suggesting that NS5A may contribute to viral persistence. Intriguingly, the glycoprotein E2 of hepatitis $C$ virus has been reported to interact with PKR and PERK, inhibiting the activities of the two kinases. ${ }^{40,90}$ While the role of the E2 protein in viral persistence remains to be established, it is possible that hepatitis $C$ virus encodes multiple functions to regulate the $E R$ stress and interferon responses.
Finally, it appears that influenza A virus has evolved mechanisms to cope with PKR and PERK. Influenza $A$ virus is a negative-stranded RNA virus that possesses a segmented genome. Of 10 proteins encoded by influenza virus, the NS1 protein functions as an inhibitor of interferon responses during cellular infection. The NS1 protein is an RNA-binding protein, which prevents the activation of PKR by dsRNA. ${ }^{91,92}$ The ability of dsRNA to stimulate phosphorylation of $\mathrm{PKR}$ is abrogated in the presence of the NS1 protein in vitro and dimerization of the NS1 protein is essential for its function. However, it has been reported that the NS1 protein directly binds to PKR and inhibits its activation. ${ }^{93}$ Whether binding of dsRNA is required for NS1 to interact with PKR is not yet resolved. Genetic analysis suggests that interaction of NS1 and PKR plays a critical role in replication of influenza A virus. ${ }^{94}$ Particularly, a recombinant virus lacking NS1 exhibits a defective viral growth in interferonproducing cells, but not in interferon-deficient cells. Thus, unlike wild-type influenza virus, infection with the NS1 deletion mutant results in hyperphosphorylation of PKR. Accordingly, similar to wild-type influenza A virus, the NS1 deletion mutant replicates efficiently in PKR-/- mice. In contrast, the NS1 deletion mutant fails to grow in PKR $+/+$ mice. ${ }^{95}$ Studies also showed that influenza virus infection leads to the activation of a cellular protein $\mathrm{p5} 8^{\mathrm{IPK}}$, which binds to and inhibits PKR activity. These experimental results suggest that influenza $A$ virus has an additional way of inhibiting PKR activity. ${ }^{63,64}$ As $\mathrm{p} 58^{\mathrm{IPK}}$ is induced by ER stress, it is interesting that p58 ${ }^{\mathrm{IPK}}$ also interacts with PERK and blocks its activity. ${ }^{62}$ However, the possible connection between influenza virus and PERK in infected cells remains to be established. Available evidence is consistent with the hypothesis that influenza $A$ virus regulates both the ER stress and interferon responses during infection. Such viral strategies would ensure suitable environment for virus infection.

\section{Conclusions}

Virus regulation of cellular responses is a critical step in determining the consequences of infection. Obviously, viruses face interferon responses mediated by PKR, which is subjected to inhibition by many viruses. Moreover, viruses encounter UPR mediated by one master control protein BiP and three sensors, PERK, ATF6. and IRE1. These components respond to viral signals emanating from the ER during viral infection. Certainly, viruses have different mechanisms to modulate this response. This complex regulation by viruses is probably evolved to either optimize viral replication or regulate the pathological process. Despite some evidence, it still remains less clear how viruses interact with each component of UPR over the course of replication. Available data suggest that PERK plays a role in limiting viral replication. In this respect, there is a crosstalk between the PERK pathway and the PKR pathway. Emerging evidence also suggests that PKR may have a role in ER stress response. The fact that viruses have developed ways to subdue both the ER stress and interferon responses suggests that these cellular pathways are crucial in controlling viral infection. Further investigation on the molecular interaction 
between viruses, the PKR pathway, and the ER stress may yield important information.

\section{Acknowledgements}

The work in this laboratory was supported by grant $\mathrm{Al} 46665(\mathrm{BH})$ from the National Institute of Allergy and Infectious Diseases. I thank Dustin Verpooten for critical reading of the manuscript.

\section{References}

1. Stark GR, Kerr IM, Williams BR, Silverman RH and Schreiber RD (1998) How cells respond to interferons. Annu. Rev. Biochem. 67: 227-264

2. Gale Jr M and Katze MG (1998) Molecular mechanisms of interferon resistance mediated by viral-directed inhibition of PKR, the interferon-induced protein kinase. Pharmacol. Ther. 78: 29-46

3. Proud CG (1995) PKR: a new name and new roles. Trends Biochem. Sci. 20: 241-246

4. Onuki R, Bando $\mathrm{Y}$, Suyama E, Katayama T, Kawasaki T, Baba T, Tohyama M and Taira K (2004) An RNA-dependent protein kinase is invovled in tunicamycin-induced apoptosis and Alzheimer's disease. EMBO J. 25 : 959-968

5. Baltzis D, Qu LK, Papadopoulou S, Blais JD, Bell JC, Sonenberg N and Koromilas AE (2004) Resistance to vesicular stomatitis virus infection requires a functional cross talk between the eukaryotic translation initiation factor 2alpha kinases PERK and PKR. J. Virol. 78: 12747-12761

6. Dimcheff DE, Faasse MA, McAtee FJ and Portis JL (2004) Endoplasmic reticulum (ER) stress induced by a neurovirulent mouse retrovirus is associated with prolonged BiP binding and retention of a viral protein in the ER. J. Biol. Chem. 279: 33782-33790

7. Sun M, Rothermel TA, Shuman L, Aligo JA, Xu S, Lin Y, Lamb RA and He B (2004) Conserved cysteine-rich domain of paramyxovirus simian virus $5 \mathrm{~V}$ protein plays an important role in blocking apoptosis. J. Virol. 78: 5068-5078

8. Netherton CL, Parsley JC and Wileman T (2004) African swine fever virus inhibits induction of the stress-induced proapoptotic transcription factor $\mathrm{CHOP} /$ GADD153. J. Virol. 78: 10825-10828

9. Tardif KD, Waris G and Siddiqui A (2005) Hepatitis C virus, ER stress, and oxidative stress. Trends Microbiol. 13: 159-163

10. Jordan R, Wang L, Graczyk TM, Block TM and Romano PR (2002) Replication of a cytopathic strain of bovine viral diarrhea virus activates PERK and induces endoplasmic reticulum stress-mediated apoptosis of MDBK cells. J. Virol. 76 9588-9599

11. Su HL, Liao CL and Lin YL (2002) Japanese encephalitis virus infection initiates endoplasmic reticulum stress and an unfolded protein response. J. Virol. 76: 4162-4171

12. Dorner AJ, Wasley LC and Kaufman RJ (1992) Overexpression of GRP78 mitigates stress induction of glucose regulated proteins and blocks secretion of selective proteins in Chinese hamster ovary cells. EMBO J. 11: 1563-1571

13. Bertolotti A, Zhang Y, Hendershot LM, Harding HP and Ron D (2000) Dynamic interaction of BiP and ER stress transducers in the unfolded-protein response. Nat. Cell Biol. 2: 326-332

14. Shen J, Chen $X$, Hendershot $L$ and Prywes $R$ (2002) ER stress regulation of ATF6 localization by dissociation of BiP/GRP78 binding and unmasking of Golgi localization signals. Dev. Cell 3: 99-111

15. Zhang K and Kaufman RJ (2004) Signaling the unfolded protein response from the endoplasmic reticulum. J. Biol. Chem. 279: 25935-25938

16. Liu CY, Xu Z and Kaufman RJ (2003) Structure and intermolecular interactions of the luminal dimerization domain of human IRE1alpha. J. Biol. Chem. 278 $17680-17687$

17. Harding HP, Calfon M, Urano F, Novoa I and Ron D (2002) Transcriptional and translational control in the mammalian unfolded protein response. Annu. Rev. Cell. Dev. Biol. 18: 575-599

18. Bitko V and Barik S (2001) An endoplasmic reticulum-specific stress-activated caspase (caspase-12) is implicated in the apoptosis of A549 epithelial cells by respiratory syncytial virus. J. Cell. Biochem. 80: 441-454
19. Li XD, Lankinen H, Putkuri N, Vapalahti $O$ and Vaheri $A$ (2005) Tula hantavirus triggers pro-apoptotic signals of ER stress in Vero E6 cells. Virology 333 : 180-189

20. Cheng G, Feng $Z$ and He B (2005) Herpes simplex virus 1 infection activates the endoplasmic reticulum resident kinase PERK and mediates elF-2 $\alpha$ dephosphorylation by the $\gamma_{1} 34.5$ protein. J. Virol. 79: 1379-1388

21. Isler JA, Skalet AH and Alwine JC (2005) Human cytomegalovirus infection activates and regulates the unfolded protein response. J. Virol. 79: 6890-6899

22. Morris JA, Dorner AJ, Edwards CA, Hendershot LM and Kaufman RJ (1997) Immunoglobulin binding protein $(\mathrm{BiP})$ function is required to protect cells from endoplasmic reticulum stress but is not required for the secretion of selective proteins. J. Biol. Chem. 272: 4327-4334

23. Peluso RW, Lamb RA and Choppin PW (1978) Infection with paramyxoviruses stimulates synthesis of cellular polypeptides that are also stimulated in cells transformed by Rous sarcoma virus or deprived of glucose. Proc. Natl. Acad. Sci. USA 75: 6120-6124

24. Watowich SS, Morimoto RI and Lamb RA (1991) Flux of the paramyxovirus hemagglutinin-neuraminidase glycoprotein through the endoplasmic reticulum activates transcription of the GRP78-BiP gene. J. Virol. 65: 3590-3597

25. Hurtley SM, Bole DG, Hoover-Litty H, Helenius A and Copeland CS (1989) Interactions of misfolded influenza virus hemagglutinin with binding protein (BiP). J. Cell. Biol. 108: 2117-2126

26. Kozutsumi Y, Segal M, Normington K, Gething MJ and Sambrook J (1988) The presence of malfolded proteins in the endoplasmic reticulum signals the induction of glucose-regulated proteins. Nature 332: 462-464

27. Liberman E, Fong YL, Selby MJ, Choo QL, Cousens L, Houghton M and Yen TS (1999) Activation of the grp78 and grp94 promoters by hepatitis C virus E2 envelope protein. J. Virol. 73: 3718-3722

28. Choukhi A, Ung S, Wychowski C and Dubuisson J (1998) Involvement of endoplasmic reticulum chaperones in the folding of hepatitis $C$ virus glycoproteins. J. Virol. 72: 3851-3858

29. Tardif KD, Mori K and Siddiqui A (2002) Hepatitis $C$ virus subgenomic replicons induce endoplasmic reticulum stress activating an intracellular signaling pathway. J. Virol. 76: 7453-7459

30. $\mathrm{Ng} \mathrm{DT}$, Randall RE and Lamb RA (1989) Intracellular maturation and transport of the SV5 type II glycoprotein hemagglutinin-neuraminidase: specific and transient association with GRP78-BiP in the endoplasmic reticulum and extensive internalization from the cell surface. J. Cell. Biol. 109: 3273-3289

31. Machamer CE, Doms RW, Bole DG, Helenius A and Rose JK (1990) Heavy chain binding protein recognizes incompletely disulfide-bonded forms of vesicular stomatitis virus $G$ protein. J. Biol. Chem. 265: 6879-6883

32. Novoa I, Zhang Y, Zeng H, Jungreis R, Harding HP and Ron D (2003) Stress-induced gene expression requires programmed recovery from translational repression. EMBO J. 22: 1180-1187

33. Zinszner H, Kuroda M, Wang X, Batchvarova N, Lightfoot RT, Remotti $\mathrm{H}$, Stevens JL and Ron D (1998) CHOP is implicated in programmed cell death in response to impaired function of the endoplasmic reticulum. Genes Dev. 12: 982-995

34. Zhan Q, Lord KA, Alamo Jr. I, Hollander MC, Carrier F, Ron D, Kohn KW, Hoffman B, Liebermann DA and Fornace Jr. AJ (1994) The gadd and MyD genes define a novel set of mammalian genes encoding acidic proteins that synergistically suppress cell growth. Mol. Cell. Biol. 14: 2361-2371

35. He B, Chou J, Liebermann DA, Hoffman B and Roizman B (1996) The carboxyl terminus of the murine MyD116 gene substitutes for the corresponding domain of the $\gamma_{1} 34.5$ gene of herpes simplex virus to preclude the premature shutoff of total protein synthesis in infected human cells. J. Virol. 70: 84-90

36. He B, Gross M and Roizman B (1997) The $\gamma_{1} 34.5$ protein of herpes simplex virus 1 complexes with protein phosphatase $1 \alpha$ to dephosphorylate the alpha subunit of the eukaryotic translation initiation factor 2 and preclude the shutoff of protein synthesis by double-stranded RNA-activated protein kinase. Proc. Natl. Acad. Sci. USA 94: 843-848

37. Boyce M, Bryant KF, Jousse C, Long K, Harding HP, Scheuner D, Kaufman RJ, Ma D, Coen DM, Ron D and Yuan J (2005) A selective inhibitor of elF2alpha dephosphorylation protects cells from ER stress. Science 307: 935-939

38. Novoa I, Zeng H, Harding HP and Ron D (2001) Feedback inhibition of the unfolded protein response by GADD34-mediated dephosphorylation of elF2alpha. J. Cell. Biol. 153: 1011-1022

39. Tirosh B, Iwakoshi NN, Lilley BN, Lee AH, Glimcher LH and Ploegh HL (2005) Human cytomegalovirus protein US11 provokes an unfolded protein response 
that may facilitate the degradation of class I major histocompatibility complex products. J. Virol. 79: 2768-2779

40. Pavio N, Romano PR, Graczyk TM, Feinstone SM and Taylor DR (2003) Protein synthesis and endoplasmic reticulum stress can be modulated by the hepatitis $C$ virus envelope protein E2 through the eukaryotic initiation factor 2alpha kinase PERK. J. Virol. 77: 3578-3585

41. Yoshida H, Matsui T, Hosokawa N, Kaufman RJ, Nagata K and Mori K (2003) A time-dependent phase shift in the mammalian unfolded protein response. Dev. Cell. 4: 265-271

42. Yoshida H, Matsui T, Yamamoto A, Okada T and Mori $\mathrm{K}$ (2001) XBP1 mRNA is induced by ATF6 and spliced by IRE1 in response to ER stress to produce a highly active transcription factor. Cell 107: 881-891

43. Tardif KD, Mori K, Kaufman RJ and Siddiqui A (2004) Hepatitis C virus suppresses the IRE1-XBP1 pathway of the unfolded protein response. J. Biol. Chem. 279: 17158-17164

44. Tardif KD and Siddiqui A (2003) Cell surface expression of major histocompatibility complex class I molecules is reduced in hepatitis $C$ virus subgenomic replicon-expressing cells. J. Virol. 77: 11644-11650

45. McCullough KD, Martindale JL, Klotz LO, Aw TY and Holbrook NJ (2001) Gadd153 sensitizes cells to endoplasmic reticulum stress by downregulating $\mathrm{Bcl} 2$ and perturbing the cellular redox state. Mol. Cell. Biol. 21: 1249-1259

46. Yoneda T, Imaizumi K, Oono K, Yui D, Gomi F, Katayama T and Tohyama M (2001) Activation of caspase-12, an endoplastic reticulum (ER) resident caspase, through tumor necrosis factor receptor-associated factor 2-dependent mechanism in response to the ER stress. J. Biol. Chem. 276: 13935-13940

47. Nakagawa T, Zhu H, Morishima N, Li E, Xu J, Yankner BA and Yuan J (2000) Caspase-12 mediates endoplasmic-reticulum-specific apoptosis and cytotoxicity by amyloid-beta. Nature 403: 98-103

48. Urano F, Wang X, Bertolotti A, Zhang Y, Chung P, Harding HP and Ron D (2000) Coupling of stress in the ER to activation of JNK protein kinases by transmembrane protein kinase IRE1. Science 287: 664-666

49. Ron D (2002) Translational control in the endoplasmic reticulum stress response. J. Clin. Invest. 110: 1383-1388

50. Wek RC (1994) elF-2 kinases: regulators of general and gene-specific translation initiation. Trends Biochem. Sci. 19: 491-496

51. Chong KL, Feng L, Schappert K, Meurs E, Donahue TF, Friesen JD, Hovanessian AG and Williams BR (1992) Human p68 kinase exhibits growth suppression in yeast and homology to the translational regulator GCN2. EMBO J. 11: 1553-1562

52. Barber GN, Tomita J, Garfinkel MS, Meurs E, Hovanessian A and Katze MG (1992) Detection of protein kinase homologues and viral RNA-binding domains utilizing polyclonal antiserum prepared against a baculovirus-expressed ds RNA-activated 68,000-Da protein kinase. Virology 191: 670-679

53. Koromilas AE, Roy S, Barber GN, Katze MG and Sonenberg N (1992) Malignant transformation by a mutant of the IFN-inducible dsRNA-dependent protein kinase. Science 257: 1685-1689

54. Lee SB and Esteban M (1994) The interferon-induced double-stranded RNA-activated protein kinase induces apoptosis. Virology 199: 491-496

55. Srivastava SP, Kumar KU and Kaufman RJ (1998) Phosphorylation of eukaryotic translation initiation factor 2 mediates apoptosis in response to activation of the double-stranded RNA-dependent protein kinase. J. Biol. Chem. 273: 2416-2423

56. Der SD, Yang YL, Weissmann C and Williams BR (1997) A double-stranded RNA-activated protein kinase-dependent pathway mediating stress-induced apoptosis. Proc. Natl. Acad. Sci. USA 94: 3279-3283

57. Chu WM, Ostertag D, Li ZW, Chang L, Chen Y, Hu Y, Williams B, Perrault J and Karin M (1999) JNK2 and IKKbeta are required for activating the innate response to viral infection. Immunity 11: 721-731

58. Goh KC, deVeer MJ and Williams BR (2000) The protein kinase PKR is required for p38 MAPK activation and the innate immune response to bacterial endotoxin. EMBO J. 19: 4292-4297

59. Patel RC and Sen GC (1998) PACT, a protein activator of the interferoninduced protein kinase, PKR. EMBO J. 17: 4379-4390

60. Ito T, Yang M and May WS (1999) RAX, a cellular activator for double-stranded RNA-dependent protein kinase during stress signaling. J. Biol. Chem. 274: 15427-15432

61. Polyak SJ, Tang N, Wambach M, Barber GN and Katze MG (1996) The P58 cellular inhibitor complexes with the interferon-induced, double-stranded RNA- dependent protein kinase, PKR, to regulate its autophosphorylation and activity. J. Biol. Chem. 271: 1702-1707

62. Yan W, Frank CL, Korth MJ, Sopher BL, Novoa I, Ron D and Katze MG (2002) Control of PERK elF2alpha kinase activity by the endoplasmic reticulum stress-induced molecular chaperone P58IPK. Proc. Natl. Acad. Sci. USA 99: 15920-15925

63. Lee TG, Tomita J, Hovanessian AG and Katze MG (1990) Purification and partial characterization of a cellular inhibitor of the interferon-induced protein kinase of Mr 68,000 from influenza virus-infected cells. Proc. Natl. Acad. Sci. USA 87: 6208-6212

64. Lee TG, Tomita J, Hovanessian AG and Katze MG (1992) Characterization and regulation of the 58000 -dalton cellular inhibitor of the interferon-induced, dsRNA-activated protein kinase. J. Biol. Chem. 267: 14238-14243

65. Melville MW, Tan SL, Wambach M, Song J, Morimoto RI and Katze MG (1999) The cellular inhibitor of the PKR protein kinase, P58(IPK), is an influenza virusactivated co-chaperone that modulates heat shock protein 70 activity. J. Biol. Chem. 274: 3797-3803

66. Chou J, Chen JJ, Gross M and Roizman B (1995) Association of a M(r) 90000 phosphoprotein with protein kinase PKR in cells exhibiting enhanced phosphorylation of translation initiation factor elF-2 $\alpha$ and premature shutoff of protein synthesis after infection with $\gamma_{1} 34.5$ - mutants of herpes simplex virus 1. Proc. Natl. Acad. Sci. USA 92: $10516-10520$

67. He B, Gross M and Roizman B (1998) The $\gamma_{1} 34.5$ protein of herpes simplex virus 1 has the structural and functional attributes of a protein phosphatase 1 regulatory subunit and is present in a high molecular weight complex with the enzyme in infected cells. J. Biol. Chem. 273: 20737-20743

68. Cheng G, Brett ME and He B (2001) Val ${ }^{193}$ and Phe ${ }^{195}$ of the $\gamma_{1} 34.5$ protein of herpes simplex virus 1 are required for viral resistance to interferona/b. Virology 290: $115-120$

69. Kazemi S, Papadopoulou S, Li S, Su Q, Wang S, Yoshimura A, Matlashewski G, Dever TE and Koromilas AE (2004) Control of alpha subunit of eukaryotic translation initiation factor 2 (elF2 alpha) phosphorylation by the human papillomavirus type $18 \mathrm{E} 6$ oncoprotein: implications for elF2 alpha-dependent gene expression and cell death. Mol. Cell. Biol. 24: 3415-3429

70. Mulvey M, Camarena V and Mohr I (2004) Full resistance of herpes simplex virus type 1 -infected primary human cells to alpha interferon requires both the Us11 and $\gamma_{1} 34.5$ gene products. J. Virol. 78: 10193-10196

71. Peters GA, Hartmann R, Qin J and Sen GC (2001) Modular structure of PACT: distinct domains for binding and activating PKR. Mol. Cell. Biol. 21: 1908-1920

72. Mohr I and Gluzman $Y$ (1996) A herpesvirus genetic element which affects translation in the absence of the viral GADD34 function. EMBO J. 15: 4759-4766

73. Beattie E, Paoletti E and Tartaglia J (1995) Distinct patterns of IFN sensitivity observed in cells infected with vaccinia K3L- and E3L- mutant viruses. Virology 210: 254-263

74. Chang HW, Uribe LH and Jacobs BL (1995) Rescue of vaccinia virus lacking the E3L gene by mutants of E3L. J. Virol. 69: 6605-6608

75. Langland JO and Jacobs BL (2002) The role of the PKR-inhibitory genes, E3L and K3L, in determining vaccinia virus host range. Virology 299: 133-141

76. Brandt TA and Jacobs BL (2001) Both carboxy- and amino-terminal domains of the vaccinia virus interferon resistance gene, E3L, are required for pathogenesis in a mouse model. J. Virol. 75: 850-856

77. Beattie E, Tartaglia J and Paoletti E (1991) Vaccinia virus-encoded elF-2 alpha homolog abrogates the antiviral effect of interferon. Virology 183: 419-422

78. Sood R, Porter AC, Ma K, Quilliam LA and Wek RC (2000) Pancreatic eukaryotic initiation factor-2alpha kinase (PEK) homologues in humans, Drosophila melanogaster and Caenorhabditis elegans that mediate translational control in response to endoplasmic reticulum stress. Biochem. J. 346: 281-293

79. Langland JO and Jacobs BL (2004) Inhibition of PKR by vaccinia virus: role of the $\mathrm{N}$ - and C-terminal domains of E3L. Virology 324: 419-429

80. Child SJ, Hakki M, De Niro KL and Geballe AP (2004) Evasion of cellular antiviral responses by human cytomegalovirus TRS1 and IRS1. J. Virol. 78: 197-205

81. Gale Jr. MJ, Korth MJ, Tang NM, Tan SL, Hopkins DA, Dever TE, Polyak SJ, Gretch DR and Katze MG (1997) Evidence that hepatitis C virus resistance to interferon is mediated through repression of the PKR protein kinase by the nonstructural 5 A protein. Virology 230: 217-227 
82. Enomoto N, Sakuma I, Asahina Y, Kurosaki M, Murakami T, Yamamoto C Izumi N, Marumo F and Sato C (1995) Comparison of full-length sequences of interferon-sensitive and resistant hepatitis $C$ virus $1 \mathrm{~b}$. Sensitivity to interferon is conferred by amino acid substitutions in the NS5A region. J. Clin. Invest. 96: 224-230

83. Watanabe $\mathrm{H}$, Enomoto $\mathrm{N}$, Nagayama K, Izumi N, Marumo F, Sato $\mathrm{C}$ and Watanabe M (2001) Number and position of mutations in the interferon (IFN) sensitivity-determining region of the gene for nonstructural protein $5 \mathrm{~A}$ correlate with IFN efficacy in hepatitis C virus genotype $1 \mathrm{~b}$ infection. J. Infect. Dis. 183: $1195-1203$

84. Gale Jr. M, Blakely CM, Kwieciszewski B, Tan SL, Dossett M, Tang NM, Korth MJ, Polyak SJ, Gretch DR and Katze MG (1998) Control of PKR protein kinase by hepatitis $C$ virus nonstructural $5 \mathrm{~A}$ protein: molecular mechanisms of kinase regulation. Mol. Cell. Biol. 18: 5208-5218

85. Gale Jr. M, Kwieciszewski B, Dossett M, Nakao H and Katze MG (1999) Antiapoptotic and oncogenic potentials of hepatitis $\mathrm{C}$ virus are linked to interferon resistance by viral repression of the PKR protein kinase. J. Virol. 73: 6506-6516

86. Nousbaum J, Polyak SJ, Ray SC, Sullivan DG, Larson AM, Carithers Jr. RL and Gretch DR (2000) Prospective characterization of full-length hepatitis $C$ virus NS5A quasispecies during induction and combination antiviral therapy. J. Virol. 74: 9028-9038

87. Duverlie G, Khorsi H, Castelain S, Jaillon O, Izopet J, Lunel F, Eb F, Penin F and Wychowski C (1998) Sequence analysis of the NS5A protein of European hepatitis $C$ virus $1 \mathrm{~b}$ isolates and relation to interferon sensitivity. J. Gen. Virol. 79 (Part 6): 1373-1381

88. Tan SL and Katze MG (2001) How hepatitis $C$ virus counteracts the interferon response: the jury is still out on NS5A. Virology 284: 1-12

89. Pflugheber J, Fredericksen B, Sumpter Jr. R, Wang C, Ware F, Sodora DL and Gale Jr. M (2002) Regulation of PKR and IRF-1 during hepatitis $C$ virus RNA replication. Proc. Natl. Acad. Sci. USA 99: 4650-4655

90. Taylor DR, Shi ST, Romano PR, Barber GN and Lai MM (1999) Inhibition of the interferon-inducible protein kinase PKR by HCV E2 protein. Science 285: $107-110$

91. Lu Y, Wambach M, Katze MG and Krug RM (1995) Binding of the influenza virus NS1 protein to double-stranded RNA inhibits the activation of the protein kinase that phosphorylates the elF-2 translation initiation factor. Virology 214: 222-228

92. Hatada $E$ and Fukuda R (1992) Binding of influenza A virus NS1 protein to dsRNA in vitro. J. Gen. Virol. 73: 3325-3329

93. Tan SL and Katze MG (1998) Biochemical and genetic evidence for complex formation between the influenza A virus NS1 protein and the interferon-induced PKR protein kinase. J. Interferon Cytokine Res. 18: 757-766

94. Garcâia-Sastre A, Egorov A, Matassov D, Brandt S, Levy DE, Durbin JE, Palese $P$ and Muster T (1998) Influenza A virus lacking the NS1 gene replicates in interferon-deficient systems. Virology 252: 324-330

95. Bergmann M, Garcia-Sastre A, Carnero E, Pehamberger H, Wolff K, Palese P and Muster T (2000) Influenza virus NS1 protein counteracts PKR-mediated inhibition of replication. J. Virol. 74: 6203-6206 